\title{
Pyrimidine-Substituted Hexaarylbenzenes as Versatile Building Blocks for N-Doped Organic Materials
}

\author{
Nicolas Meitinger ${ }^{a}$ (D) \\ Alexander K. Mengele ${ }^{a}$ (i) \\ Djawed Nauroozi*a (D) \\ Sven Rau*a (iD) \\ a Ulm University, Institute of Inorganic Chemistry I, Albert-Einstein-Allee 11, 89081 \\ Ulm, Germany \\ djawed.nauroozi@gmail.com; sven.rau@uni-ulm.de \\ Dedicated to Prof. Dr. Peter Bäuerle in occasion of his 65th birthday.
}

Received: 26.02.2021

Accepted after revision: 03.04.2021

DOI: 10.1055/a-1482-6190; Art ID: om-21-0023oa

License terms: CCO

(c) 2021. The Author(s). This is an open access article published by Thieme under the terms of the Creative Commons Attribution-NonDerivative-NonCommercial License, permitting copying and reproduction so long as the original work is given appropriate credit. Contents may not be used for commercial purposes, or adapted, remixed, transformed or built upon. (https://creativecommons.org/licenses/by-nc-nd/4.0/)

Abstract Hexaarylbenzenes (HABs) are valuable precursors for the bottom-up synthesis of (nano-)graphene structures. In this work the synthesis of several bis-pyrimidine substituted HABs furnished with tertbutyl groups at different sites of the four pendant phenyl rings is reported. The synthetic procedure is based on modular [ $4+2]$-DielsAlder cycloaddition reactions followed by decarbonylation. Analysis of the solid-state structures revealed that the newly synthesized HABs feature a propeller-like arrangement of the six arylic substituents around the benzene core. Here, the tilt of the aryl rings with respect to the central ring strongly depends on the intermolecular interactions between the HABs and co-crystallized solvent molecules. Interestingly, by evading the closest proximity of the central ring using an alkyne spacer, the distant pyrimidine ring is oriented in the coplanar geometry with regard to the benzene core, giving rise to a completely different UV-absorption profile.

Key words carbon materials, cycloadditions, Diels-Alder reactions, doping, ligand design, N-heterocycles

\section{Introduction}

The broad variety of substituted benzenes accessible when replacing all hydrogen atoms with (up to six different) substituents ${ }^{1,2}$ renders a rich chemistry and provides manifold applications related to organic materials. Furnishing the benzene core with six aromatic $\pi$-systems leads to socalled hexaarylbenzenes (HABs), ${ }^{3}$ which render access to the design of, inter alia, supramolecular electronic materials, ${ }^{4}$ molecular rotors, ${ }^{5}$ redox materials, ${ }^{6}$ non-linear optical

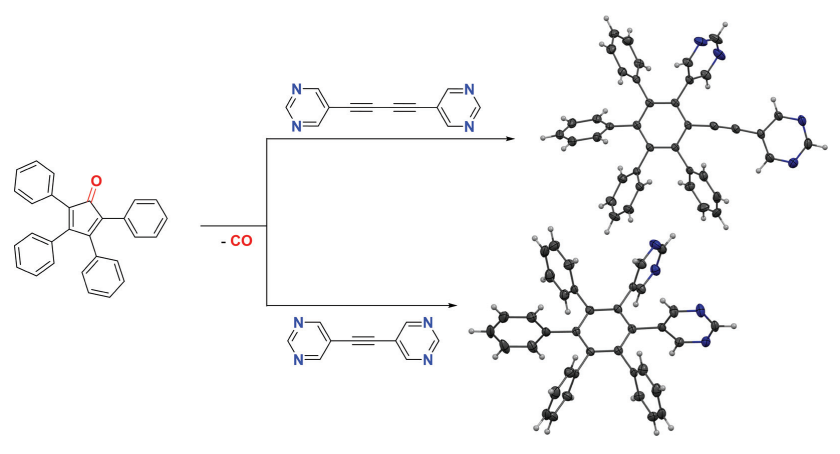

materials, ${ }^{7}$ molecular wires and metal sensors. ${ }^{8}$ Synthetically, either $[2+2+2]$-cyclotrimerization ${ }^{9-12}$ of 1,2-diarylacetylenes or subsequent [4+2]-Diels-Alder cycloaddition/ decarbonylation sequences between a tetraaryl cyclopentadienone and a suitable dienophile ${ }^{13-15}$ (1,2-diaryl-acetylene or 1,2-diarylethene) are primarily used in order to obtain hexaaryl-substituted benzenes, although elegant alternative routes have been successfully applied, as well. ${ }^{16,17}$ The modular approach given in Diels-Alder type reactions allows, however, the access of distinct structural motifs upon careful use of precursor building blocks. ${ }^{18}$ In this context, the use of cyclopentadienones, which allow the introduction of different substituents along with the rich photophysical and electrochemical properties, certainly underlines the versatility of this route. ${ }^{19}$ Apart from intensively studied properties of HABs with regard to inter- ${ }^{20,21}$ and intramolecular ${ }^{22,23}$ interactions, aggregation properties ${ }^{24}$ or tuning of the HOMO-LUMO gap, 25,26 among others, the role of HABs themselves as precursors for doped (nano-)graphene structures ${ }^{27}$ turns more rapidly into focus. As such, S- and $\mathrm{N}$-doped carbon-rich molecules are of great importance as they allow tuning of the electronic nature of expanded $\pi$ surfaces. ${ }^{28}$ Although very promising materials, the number of heteroatom-doped $\pi$-surfaces is still low, probably due to the challenging synthesis.

Among those, Draper and co-workers have impressively shown the synthesis and dehydrogenation of $\mathbf{6 d}$ using $\mathrm{AlCl}_{3}$ / $\mathrm{CuCl}_{2}{ }^{18}$ or $\mathrm{FeCl}_{3},{ }^{29}$ gaining access to large conjugated chelating "heterosuperbenzene" ligands. ${ }^{30}$ We herein aim to extend the variety of such $\mathrm{N}$-doped "heterosuperbenzene" precursors by derivatives $\mathbf{6 a}-\mathbf{c}$, bearing less sterically demanding tert-Bu groups. These are promising compounds to be used for the design of transition metal-mediated supramolecular assemblies, or, upon their dehydrogenative aromatic coupling, as $\mathrm{N}$-doped nanographene motifs for chelation allowing the study of their influence on their supramolecular interactions. 


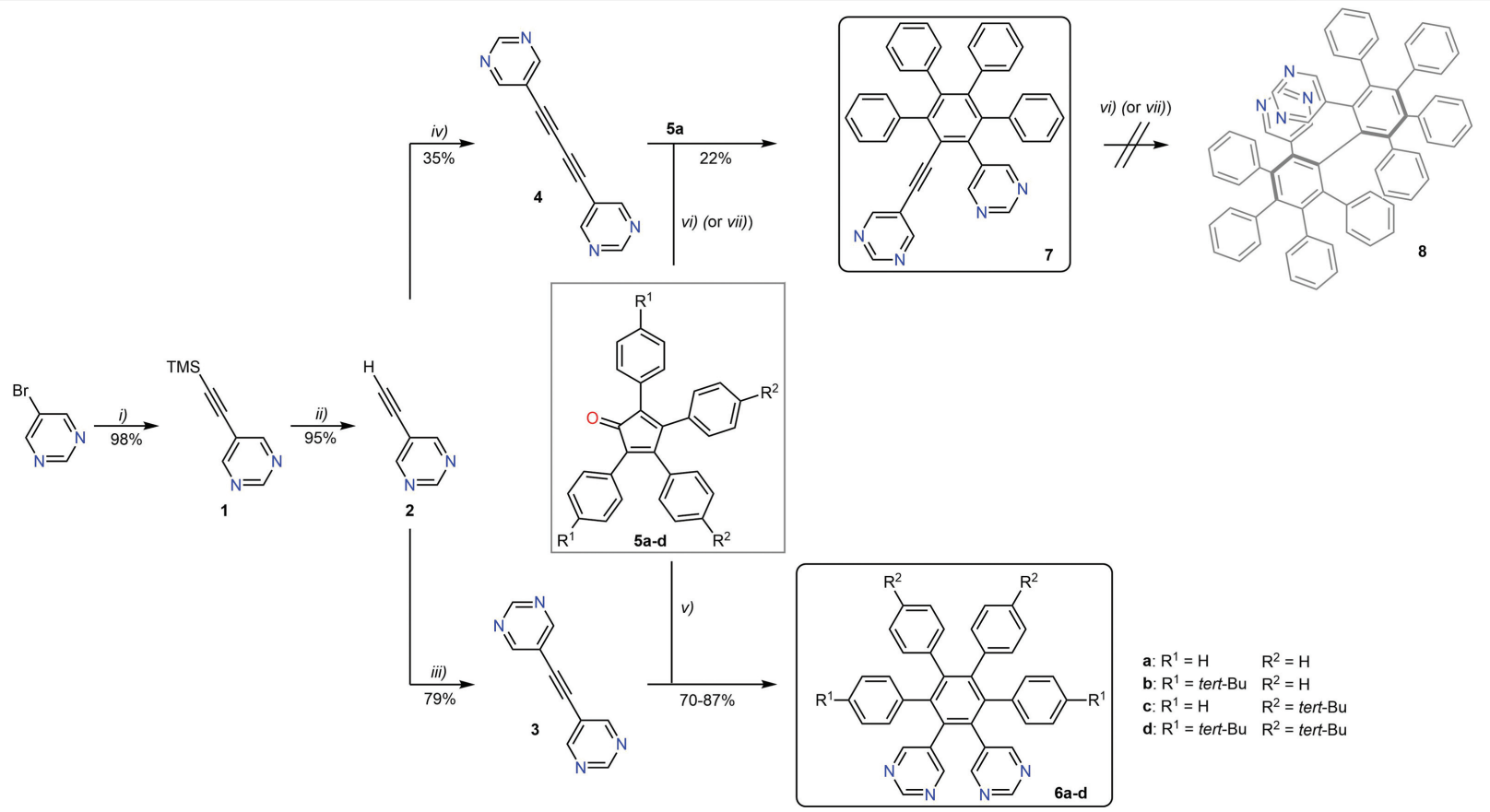

Scheme 1 Introduction of N-dopants into hexaarylbenzene derivatives $\mathbf{6 a - d}$ via [4+2] cycloaddition/decarbonylation of tolane $\mathbf{3}$ using tetracyclones 5a-d. Alkynylated derivative $\mathbf{7}$ was obtained by an analogous reaction of diyne $\mathbf{4}$, whereas the product of a double cycloaddition/decarbonylation $\mathbf{8}$ could not be obtained. i) TMS-acetylene, [Pd( $\left.\mathrm{PPh}_{3}\right)_{2} \mathrm{Cl}_{2}$ ], Cul, $\mathrm{PPh}_{3}$, THF, TEA, $55^{\circ} \mathrm{C}, 18 \mathrm{~h}, 98 \%$; ii) $\mathrm{K}_{2} \mathrm{CO}_{3}$, THF, MeOH, RT, 2 h, 95\%; iii) 5-bromopyrimidine, [Pd $\left(\mathrm{PPh}_{3}\right)_{2} \mathrm{Cl}_{2}$ ], Cul, THF, TEA, $55^{\circ} \mathrm{C}, 18 \mathrm{~h}, 79 \%$; iv) 5-bromopyrimidine, [Pd( $\left(\mathrm{PPh}_{3}\right)_{2} \mathrm{Cl}_{2}$ ], Cul, THF, TEA, $35^{\circ} \mathrm{C}, 18 \mathrm{~h}, 35 \%$; v) 5a-d, benzophenone, $295^{\circ} \mathrm{C}, 70-87 \%$; vi) $5 \mathrm{a}, \mathrm{Ph}_{2} \mathrm{O}, 230^{\circ} \mathrm{C}, 12 \mathrm{~h}, 22 \%$; vii) $5 \mathrm{a}, 1,2-\mathrm{DCB}, 800 \mathrm{~W} \mu \mathrm{W}, 140-150{ }^{\circ} \mathrm{C}, 4 \mathrm{~h}$, ca. $90 \%$ conversion to 7.

\section{Results and Discussion}

The synthesis of ortho-pyrimidine-substituted HABs is illustrated in Scheme 1. Following standard SonogashiraHagihara conditions using a modified literature procedure, ${ }^{31}$ trimethylsilyl-protected ethynylpyrimidine $\mathbf{1}$ could be obtained in almost quantitative yield upon purification via vacuum distillation. Protodesilylation of $\mathbf{7}$ in a mixture of wet $\mathrm{MeOH} / \mathrm{THF}$ using $\mathrm{K}_{2} \mathrm{CO}_{3}$ gave 5-ethynylpyrimidine $\mathbf{6}$, which was used in another modified Sonogashira-Hagihara coupling reaction $^{31}$ at elevated temperatures of $50{ }^{\circ} \mathrm{C}$ with 5-bromopyrimidine to obtain 1,2-di(pyrimidin-5-yl)acetylene $3 .^{31,32}$

Usage of more than 2 mol-\% of CuI together with 5 mol-\% Pd-catalyst resulted in the formation of butadiyne $\mathbf{4}$ as a byproduct of $\mathbf{3}$ in 35\% yield. Very similar chemical shifts of the aryl protons in ${ }^{1} \mathrm{H}-\mathrm{NMR}$ were observed for both products (9.19, 8.88 ppm vs. 9.20, 8.88 ppm), which was also monitored in ${ }^{13} \mathrm{C}-\mathrm{NMR}$, except for the alkyne carbon atoms. Surprisingly, 4 gave only a single signal for the alkyne carbons at $79.69 \mathrm{ppm}$, whereas it was shifted downfield (89.16 ppm) in the case of 3, suggesting a higher electron density at the alkyne functions in $\mathbf{4}$ as a consequence of just one electronwithdrawing heterocycle per alkyne group. Polar solvent mixtures (EtOAc/acetone 4:1) were necessary for silica column chromatography of 3, resulting in the elution of [Pd $\left(\mathrm{PPh}_{3}\right)_{2} \mathrm{Br}_{2}$ ] that crystallized from the solvent mixture by slow evaporation (see Figure S39), as well as the co-elution of yet unidentified Pd-catalyst species, coloring the product yellow. The latter were removed by stirring a solution of the crude product together with (3-mercaptopropyl)-functionalized silica in dichloromethane [see the Supporting Information (SI)], whereas triphenyl phosphine oxide could successfully be removed via recrystallisation from ethanol. Finally, upon slow evaporation of $\mathrm{CDCl}_{3}$ from an NMR tube, 3 was obtained as an isolated single crystal for the first time (see Figures S37 and S38), allowing analysis of the solid-state structure along with its packing behavior (vide infra).

Diels-Alder reactions between tolane 3 and either 1,2,3,4tetraphenyl-cyclopentadienone $\mathbf{5 a}$ or tert-Bu-substituted derivatives (5b-d) resulted in HABs comprising two adjacent pyrimidine units in $70-87 \%$ yields (see Scheme 1 ). As a reference for the optical properties of our less substituted HABs, the literature-known compound $\mathbf{6 d}$ with four tert-Bu substituents was synthesized as well using a literature-known procedure in $80 \%$ yield ( $81 \%$ lit.). ${ }^{18}$ Inspired by previous works, ${ }^{33}$ we subjected the butadiyne 4 to Diels-Alder reaction conditions as well, expecting a two-fold $[4+2]$ cycloaddition. Upon stirring the reactants in diphenyl ether at $230^{\circ} \mathrm{C}$ for $12 \mathrm{~h}$, the product of a single cycloaddition reaction 7 was isolated in an unoptimized yield of $22 \%$. It is noteworthy that cycloaddition reactions of tolane $\mathbf{3}$ to give $\mathbf{6} \mathbf{a}$ failed at temperatures of up to $240{ }^{\circ} \mathrm{C}$. Attempts to obtain compound 8 via a two-fold 
297

THEME

Organic Materials

N. Meitinger et al.

OPEN
ACCESS

Original Article
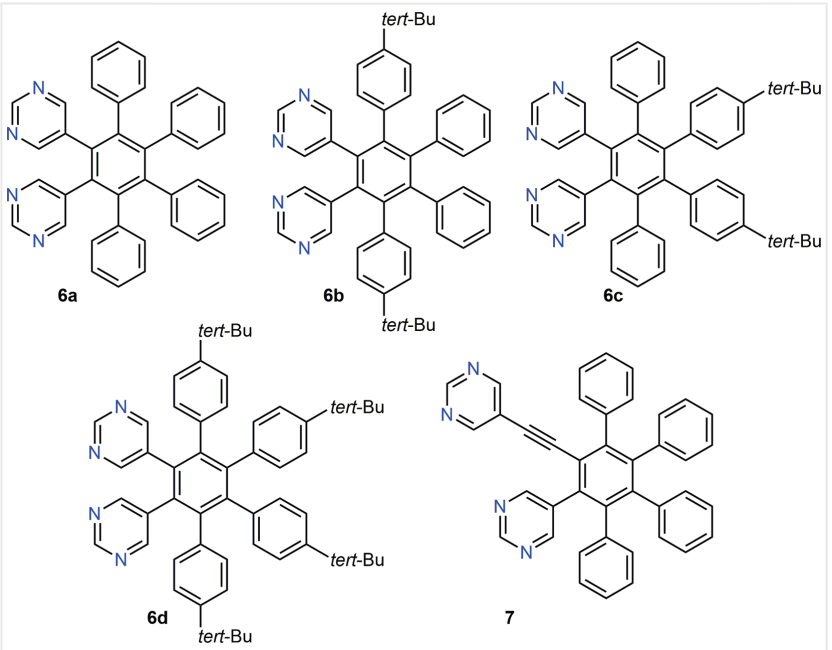

Figure $1 \mathrm{~N}$-Doped hexaarylbenzenes $\mathbf{6 a}-\mathbf{d}$ and the alkyne-functionalized derivative $\mathbf{7}$ under investigation.

Diels-Alder conversion of $\mathbf{4}$ or the subsequent conversion of $\mathbf{7}$ with an excess of $\mathbf{5 a}$ using harsh conditions (egg. $12 \mathrm{~h}$ at $280^{\circ} \mathrm{C}$ in benzophenone) as well as microwave activation ( $4 \mathrm{~h}$ at $140{ }^{\circ} \mathrm{C}$ in 1,2-DCB, almost full conversion to 7, see Figure S15) did not lead to an identified formation of $\mathbf{8}$ in the crude so far. Higher temperatures might be necessary to get access to $\mathbf{8}$, unfortunately the utilized laboratory microwave (using open vessels) did not allow to go for temperatures significantly higher than the solvent boiling point of $140^{\circ} \mathrm{C}$ as it was done in the literature. $^{33}$

A concentration dependence of NMR spectra of Diels-Alder products 6a-d and 7 shown in Figure 1 could not be found in $\mathrm{CDCl}_{3}$, indicating that the molecules do not show substantially planarized geometry which would favor $\pi-$ $\pi$-interaction-induced aggregation in solution. ${ }^{34}$ Chemical

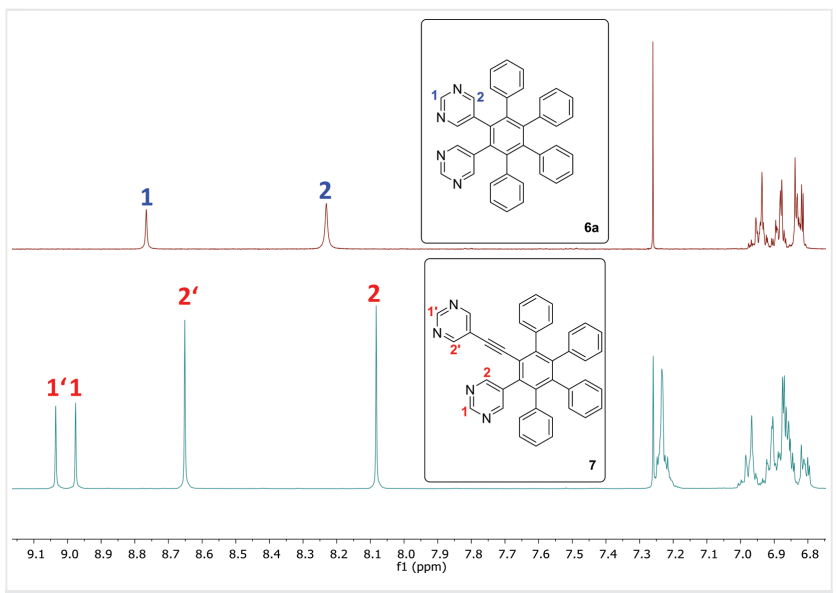

Figure 2 Comparison of the aromatic region of the ${ }^{1} \mathrm{H}-\mathrm{NMR}$ spectra (400 MHz, RT, $\mathrm{CDCl}_{3}$ ) of compounds $6 \mathbf{a}$ and 7.

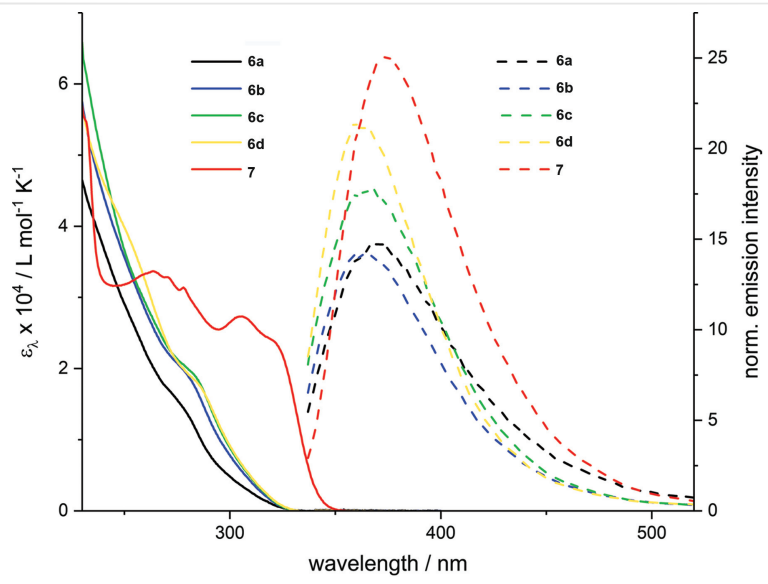

Figure 3 Electronic absorption (solid lines) and emission spectra (dashed lines, upon excitation at $280 \mathrm{~nm}$ ) of HABs 6a-d and 7. Emission was normalized to the extinction of each sample at the excitation wavelength of $280 \mathrm{~nm}\left(5 \times 10^{-6} \mathrm{M}\right.$ samples $)$.

shifts of the pyrimidine singlets found at 8.77 (H1) and $8.23 \mathrm{ppm}(\mathrm{H} 2)$ in 6a-d were unaffected by substitution of the phenyl para-positions. Upon introduction of the alkyne spacer in $\mathbf{7}$ however, the now inequivalent resonances for $\mathrm{H} 1$ and $\mathrm{H} 1$ ' found at 8.98 and $9.04 \mathrm{ppm}$, respectively, were shifted downfield by $0.21-0.27$ ppm compared to $\mathrm{H} 1$ in $\mathbf{6 a}$ (Figure 2). A similar downfield shift of $0.42 \mathrm{ppm}$ for the resonance of protons $\mathrm{H} 2$ ' could be observed in $\mathbf{7}$, as these are facing the lone pair of the neighboring heterocycle, whereas $\mathrm{H} 2$ shifted upfield by $0.15 \mathrm{ppm}$ due to the shielding alkyne spacer.

Electronic absorption and emission spectra were medsure in $\mathrm{CH}_{2} \mathrm{Cl}_{2}$, showing a rather unresolved absorption of 6a-d within the UV up to $325 \mathrm{~nm}$ (Figure 3), as can be observed for the all-carbon analogue $\mathbf{9}$ (Figure 4, Table 1 ). ${ }^{33}$ Alkyne functionalization in 7 resulted in an expanded absorption up to $350 \mathrm{~nm}$ due to the extended $\pi$-system and, in contrast to its all-carbon analogue 10, was accompanied by an increase in molar absorption coefficient.<smiles>c1ccc(-c2c(-c3ccccc3)c(-c3ccccc3)c(-c3ccccc3)c(-c3ccccc3)c2-c2ccccc2)cc1</smiles><smiles>C(#Cc1c(-c2ccccc2)c(-c2ccccc2)c(-c2ccccc2)c(-c2ccccc2)c1-c1ccccc1)c1ccccc1</smiles>

9

10

Figure 4 Structures of the all-carbon analogues hexaphenylbenzene 9 and alkyne-functionalized $\mathbf{1 0}$.

(C) 2021. The Author(s). Organic Materials 2021, 3, 295-302 
Table 1 Electronic absorption and emission data of polyphenylenes 9 and $10^{\text {a }}$

\begin{tabular}{lll}
\hline & $\lambda_{\text {abs }}[\mathrm{nm}]$ & $\lambda_{\mathrm{em}}[\mathrm{nm}]$ \\
\hline $\mathbf{9}$ & $254,282(\mathrm{~s})$ & 333 \\
$\mathbf{1 0}$ & $259,304,319$ & 344
\end{tabular}

${ }^{a}$ Measured in methylene chloride; maximum given in italics; (s) denotes shoulder; data from Ref. 33.

Upon excitation of $5 \times 10^{-6} \mathrm{M}$ samples at $280 \mathrm{~nm}$, fluorescence maxima were found around $365 \mathrm{~nm}$ for $\mathbf{6 a - d}$, which is in the range of other pyrimidine-functionalized HABs, ${ }^{12}$ while shifted to lower energy by $32 \mathrm{~nm}$ compared to $\mathbf{9}$. In the case of $\mathbf{7}$, the emission maximum was similarly bathochromically shifted by $31 \mathrm{~nm}$ compared to $\mathbf{1 0}$ to $375 \mathrm{~nm}^{33}$ Emission intensities were normalized with respect to the compounds' absorbances at the constant excitation wavelength, showing stronger emission for 7.

In a cyclic voltammetry analysis of a $1 \mathrm{mM}$ solution of $\mathbf{6 d}$ in methylene chloride, no oxidation or reduction events could be observed within the accessible potential window given by decomposition of the solvent (see Figure S25).

Crystals of the three HABs 6a-c as well as $\mathbf{7}$ suitable for X-ray diffraction were obtained via slow evaporation of chloroform from concentrated toluene/chloroform solutions (see Figure 5). All three colorless derivatives 6a-c crystallize in the triclinic space group P-1 and feature a propeller-like arrangement of the arylic substituents around the central benzene core. The tilts of the aryl substituents of HABs $\mathbf{6 b}$ and $\mathbf{6 c}$ with respect to the central

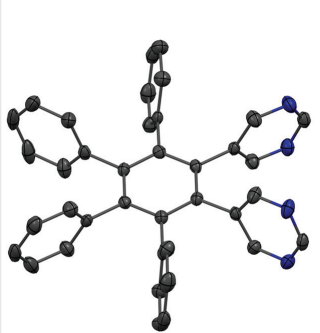

$6 a$

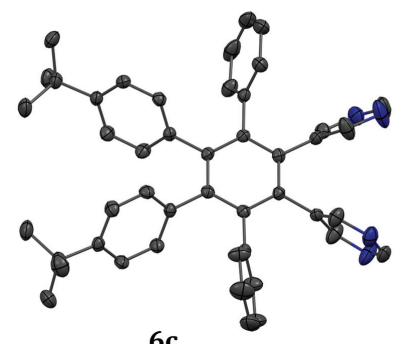

$6 c$

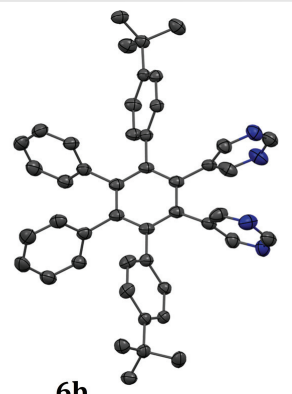

$6 \mathbf{b}$

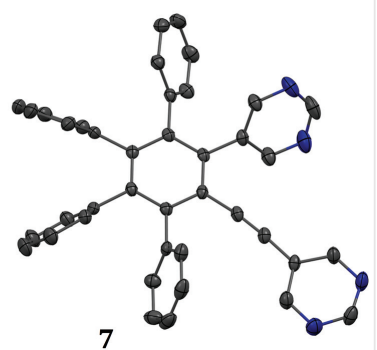

Figure $\mathbf{5}$ Solid-state structures of the HABs $\mathbf{6 a - c}$ and alkyne moiety containing derivative 7 . Ellipsoids are drawn at the $50 \%$ probability level and $\mathrm{H}$-atoms as well as co-crystallized $\mathrm{CHCl}_{3}$ were omitted for clarity. ring range from $56^{\circ}$ to $84^{\circ}$ and $64^{\circ}$ to $72^{\circ}$, respectively, which is reminiscent of the values of different other pyrimidine containing HABs featuring bromide or methoxy substituents $^{35}$ as well as tert-Bu substituents. ${ }^{12,35}$ Similarly, the torsion angles of the six thiophene substituents connected to a central benzene ring were between $51^{\circ}$ and $76^{\circ},{ }^{33}$ indicating that the size of the aryl substituents does not necessarily correlate with the observed tilts.

In strong contrast, HAB $\mathbf{6} \mathbf{a}$ features torsion angles of the substituted pyrimidine and phenyl rings which all fall in a small range of $79^{\circ}$ to $87^{\circ}$, i.e. they are all close to orthogonal orientation with respect to the benzene core. This finding can be ascribed to the unique packing of $\mathbf{6} \mathbf{a}$ in the solid state which is dominated by $\mathrm{C}-\mathrm{H}$... N interactions of co-crystallized $\mathrm{CHCl}_{3}$ and the $\mathrm{N}$-containing aryl rings, forcing the pyrimidine units to orthogonality with regard to the central ring in order to maximize the efficiency of this interaction (see Figure 6). As a result of this process, the other four phenyl rings can be aligned in a nearly perpendicular fashion as well.
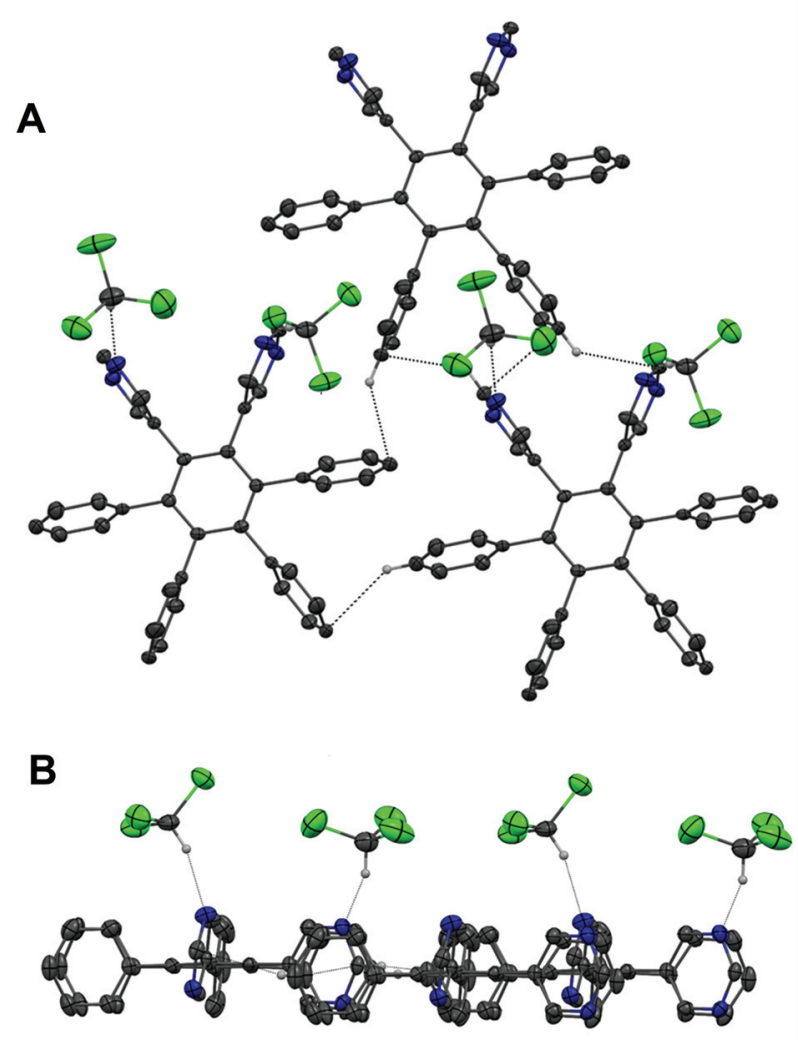

Figure 6 Top view (A) and lateral view (B) of the solid-state packing of 6a. Short contacts (intermolecular distances shorter than the sum of the van der Waals radii of the individual atoms by at least $0.1 \AA$ ) are indicated by black dashed lines. Ellipsoids are drawn at the 50\% probability level. All H-atoms not being involved in short contact interactions were omitted for clarity. 
Moreover, the combination of short distances between the ipso-C-atoms and the propeller-like architecture of such HABs was considered to allow toroidal delocalization of the $\pi$-electrons. ${ }^{33,36}$ As a result of the virtually unaltered size of the benzene core and the mostly unaffected $\mathrm{C}-\mathrm{C}$ bond length between the $\mathrm{C}$-atoms of the central ring and the ipsoC-atoms, all three HABs $\mathbf{6 a}-\mathbf{c}$ as well as all above-discussed literature-known ${ }^{12,35}$ pyrimidine-containing HABs exhibit C-C distances of the ipso-C-atoms between 280 and $297 \mathrm{pm}$, clearly falling below the sum of the combined van der Waals radii. ${ }^{37}$ Therefore, also for the herein-prepared HABs $\mathbf{6 a}-\mathbf{c}$, toroidal delocalization of the $\pi$-electrons might be structurally feasible.

Also, for the alkyne-moiety-containing derivative $\mathbf{7}$, torsion angles of the five aryl substituents with respect to the central benzene core are between $60^{\circ}$ and $70^{\circ}$. The alkyne bond is on the one hand slightly bent by about $1.5^{\circ}$ along its main axis and on the other hand it allows the alkyne-connected pyrimidine moiety to be twisted relative to the central ring by only ca. $2.5^{\circ}$. This is reminiscent of tolane 3 and several reported derivatives of this compound class, where the alkyne-connected pyrimidine units are oriented in a coplanar geometry. ${ }^{38}$

The alkyne moiety thus permits almost complete planarization of the two-alkyne-spaced aryl rings in 7, optimizing conjugation within the system. This might explain the drastically different UV-absorption profile of 2 compared to the HABs $\mathbf{6 a}-\mathbf{d}$ which do not possess an intense absorption band between 300 and $350 \mathrm{~nm}$ (see Figure 3). It should be noted that in a very similar system that featured only thiophene substituents on the same basic structural skeleton as 7 , the alkyne-spaced thiophene ring is twisted by about $47.7^{\circ}$ with respect to the central benzene core. ${ }^{33}$

The above-mentioned tolane $\mathbf{3}$ with coplanar heterocycles crystallized in the monoclinic space group $\mathrm{P} 2 / \mathrm{n}$ from a concentrated chloroform solution. Up to now, crystals of $\mathbf{3}$ have only been obtained by co-crystallization with calix[4] resorcinarene ${ }^{39}$ or 1,3-diiodotetrafluorobenzene exploiting N...I halogen bonds for single crystal formation. ${ }^{40}$ However, several crystal structures of $-\mathrm{Cl},-\mathrm{OMe}$ or $-\mathrm{S}($ tert- $\mathrm{Bu})$ substituted derivatives of $\mathbf{3}$ have already been reported. ${ }^{38}$ As for $\mathbf{3}$, these derivatives do also feature coplanar-oriented pyrimidine rings. Moreover, similar to the previously reported derivatives, 3 also features various $\mathrm{N}-\mathrm{H}$-... interactions which define its packing in the solid state (see Figure S38). In comparison to the previously reported substituted bipyrimidine tolane derivatives and co-crystals of 3 discussed above, the obtained solid-state structure of pure, unmodified $\mathbf{3}$ does not exhibit any significant differences regarding the bond lengths. A typical value of $119.8(2) \mathrm{pm}$ for the C-C distance of the alkyne was obtained, along with a $\mathrm{C}-\mathrm{C}$ distance of the alkyne C-atoms and the respective aryl C-atoms of 143.2(3) pm each.

\section{Conclusions}

In summary, the synthesis of various bis-pyrimidinefunctionalized HABs 6a-d in 70-87\% yields using a modular synthesis route based on a [4+2]-Diels-Alder/decarbonylation pathway was reported. The analysis of the solid-state structure of HABs $\mathbf{6 a}-\mathbf{c}$ revealed in all cases a propeller-like arrangement of the arylic substituents as well as short intramolecular distances between the ipso-C-atoms, structurally enabling these molecules for possible toroidal $\pi$-electron delocalization. By utilizing a higher amount of CuI during the preparation of bis-pyrimidine tolane $\mathbf{3}$ via SonogashiraHagihara coupling, butadiyne derivative $\mathbf{4}$ could be isolated. Subjecting $\mathbf{4}$ to the synthetic strategy discussed above using $\mathbf{5 a}$ as diene moiety gave only the mono-converted product 7 with one remaining intact alkyne functionality. Very likely the high steric demand generated by the propeller-like orientation of the five aryl rings did not permit a subsequent [ $4+2]$-DielsAlder reaction/decarbonylation sequence. Upon successful dehydrogenative aromatic coupling of the less functionalized derivatives 6a-c using suitable Lewis acids and/or oxidants, the resulting heterosuperbenzenes ${ }^{18}$ might give access to fully fused $\mathrm{N}$-doped hexabenzocoronene structures that can be post-functionalized via electrophilic aromatic substitution (e.g. bromination), which has so far not been achieved. ${ }^{41}$ Furthermore, with bay regions that are not blocked by tert-Bu groups, these new derivatives might allow for further functionalization via the $[4+2]$-Diels-Alder reaction, ${ }^{42}$ opening up the possibility to produce bridging ligands.

\section{Experimental Section}

All reactions were carried out under inert conditions. Commercially available reagents were used without further purification. 1,2-Dichlorobenzene (Merck) was dried over $\mathrm{CaCl}_{2}$ and distilled prior to use. Benzophenone was purchased from Sigma Aldrich in ReagentPlus grade. All other solvents were purchased from VWR in technical grade, distilled prior to use and deaerated by gently bubbling argon through the solvents. Dry and deaerated THF and $\mathrm{CH}_{2} \mathrm{Cl}_{2}$ were taken from a MBraun SPS 800 . Tetraarylcyclopentadienones 5a-d were prepared according to literature procedures. ${ }^{19}$ Modified synthetic procedures for literature-known compounds $1-3^{31,32}$ and $\mathbf{4}^{43}$ can be found in the SI. Thin-layer chromatography was performed on aluminum plates, precoated with silica gel, Merck Si60 $\mathrm{F}_{254}$. Preparative column chromatography was carried out on glass columns packed with silica gel, Merck silica gel 60 , particle size 40-63 $\mu \mathrm{m}$. Flash chromatography was performed on an Interchim PuriFlash 430 equipped with a UV/Vis detector and silica gel columns $(12 \mathrm{~g}, 50 \mu \mathrm{m})$. NMR spectra were recorded on a Bruker Avance III HD 400 at $293 \mathrm{~K}$ and processed with MestReNova software (version 12.0.0). 
Chemical shift values $\delta$ are given in parts per million (ppm) and were referenced using residual nondeuterated solvent peaks as an internal standard. The splitting patterns are labeled as follows: $\mathrm{s}=$ singlet, $\mathrm{d}=$ doublet, $\mathrm{t}=$ triplet, $\mathrm{q}=$ quartet, $\mathrm{m}=$ multiplet and $\mathrm{dd}=$ doublet of doublets. Constants $J$ are presented as absolute values in $\mathrm{Hz}$. Highresolution MALDI-TOF mass spectra (HRMS) were recorded on a Bruker Daltonics REFLEX III equipped with a pulsed nitrogen laser $(\lambda=337 \mathrm{~nm})$, using trans-(2-[3-(4-(tertbutyl)phenyl)-2-methyl-allylidene]malonitrile (DCTB) as a matrix. Data were processed with Bruker Daltonik Compass DataAnalysisViewer software (version 5.0). Values are given in fractions $m / z$. UV/Vis absorption spectra were recorded in quartz cuvettes with a path length of $10 \mathrm{~mm}$ using JASCO Photometers $V-670$ and $V$-760. Fluorescence spectra were recorded on a JASCO FP-8500. All experiments were performed at room temperature under aerobic conditions. FT-IR spectra were measured using a Bruker ALPHA II FT-IR spectrometer equipped with the platinum ATR accessory mounting samples in between monolithic diamond crystals. Air was used as a background in a range of $4000-400 \mathrm{~cm}^{-1}$, with 24 averaged scans and a resolution of $4 \mathrm{~cm}^{-1}$. Crystals suitable for single-crystal X-ray crystallography were mounted using a MicroLoop and perfluoropolyalkyl ether (viscosity: $1800 \mathrm{cSt}$ ). X-ray diffraction intensity data were measured at $150 \mathrm{~K}$ on a Bruker D8 Quest single-crystal diffractometer with a PHOTON II detector using Mo-K $\mathrm{K}_{\alpha}$ radiation (wavelength $\lambda=0.71073 \AA$ ). Structure solution and refinement was carried out using the SHELXL package ${ }^{44,45}$ via Olex2. Corrections for incident and diffracted beam absorption effects were applied using multi-scan refinements. Structures were solved by direct methods and refined against $\mathrm{F}^{2}$ by the full-matrix leastsquares technique. The hydrogen atoms were included at calculated positions with fixed thermal parameters. All nonhydrogen atoms were refined anisotropically unless otherwise mentioned. MERCURY was used for structural representations. ${ }^{46}$

CCDC 2064746(for 6a), 2064748 (for 6b), 2064747 (for 6c), 2064749 (for 7) and 2064745 (for 3) contain the supplementary crystallographic data for this paper. These data are provided free of charge by the joint Cambridge Crystallographic Data Centre and Fachinformationszentrum Karlsruhe Access Structures service www.ccdc.cam.ac.uk/structures.

\section{Procedures}

5,5'-(3',6'-Diphenyl-[1,1':2',1'-terphenyl]-4',5'-diyl)dipyrimidine (6a): In a $50 \mathrm{~mL}$ RB Schlenk flask, tolane $3(0.200 \mathrm{~g}$, $1.1 \mathrm{mmol})$ and tetracyclone $\mathbf{5 a}(0.422 \mathrm{~g}, 1.1 \mathrm{mmol})$ were stirred at $295{ }^{\circ} \mathrm{C}$ in benzophenone ( $3 \mathrm{~g}$ ) under an argon atmosphere for $2 \mathrm{~h}$. Upon cooling to room temperature, the crude was dispersed in diethyl ether $(3 \times 20 \mathrm{~mL})$ and the solutions decanted to leave behind an off-white powder (0.450 g, 76\%), mp $>300{ }^{\circ} \mathrm{C}$.

ATR-IR (neat): 3055, 3024, 2923, 1602, 1577, 1546, 1497, 1443, 1418, 1392, 1342, 1315, 1276, 1262, 1186, 1159, 1120, 1105, 1072, 1052, 1029, 1000, 910, 811, 790, 745, 729, 698, $630,562,529,508 \mathrm{~cm}^{-1}$.

${ }^{1} \mathrm{H} \mathrm{NMR}\left(\mathrm{CDCl}_{3}, 400 \mathrm{MHz}\right): \delta=8.77\left(\mathrm{~s}, 2 \mathrm{H}, \mathrm{H}^{\mathrm{Py}-2}\right), 8.23$ (s, $\left.4 \mathrm{H}, \mathrm{H}^{\mathrm{Py}-4 / 6}\right), 6.98-6.81\left(\mathrm{~m}, 20 \mathrm{H}, \mathrm{H}^{\mathrm{Ph}}\right) \mathrm{ppm}$.

${ }^{13} \mathrm{C} \mathrm{NMR}\left(\mathrm{CDCl}_{3}, 101 \mathrm{MHz}\right): \delta=158.10,156.24,142.79$, 141.77, 139.29, 138.65, 133.28, 131.14, 130.98, 127.71, 127.06, 126.68, 126.07 ppm.

HRMS (MALDI): $m / z[\mathrm{M}+\mathrm{H}]^{+}$calcd for $\mathrm{C}_{38} \mathrm{H}_{27} \mathrm{~N}_{4}{ }^{+}$: 539.22302; found: 539.22370 .

Crystals suitable for X-ray diffraction were obtained from toluene/chloroform. Crystal data: $\mathrm{C}_{19} \mathrm{H}_{13} \mathrm{~N}_{2} \cdot 2 \mathrm{CHCl}_{3}$, $M_{\mathrm{r}}=508.05 \mathrm{~g} \mathrm{~mol}^{-1}$, colourless plate, $0.052 \times 0.256$ $\times 0.362 \mathrm{~mm}^{3}$, triclinic, space group P-1, $a=11.9046(6)$ $\AA, b=12.0806(7) \AA, c=19.0468(11) \AA, \alpha=73.361(3)^{\circ}$, $\beta=83.888(3)^{\circ}, \quad \gamma=61.440(2)^{\circ}, \quad V=2303.7(2) \quad \AA^{3}, \quad T$ $=150.00 \mathrm{~K}, \quad Z=4, \quad \rho_{\text {calcd. }}=1.465 \mathrm{Mg} / \mathrm{m}^{3}, \quad \mu\left(\right.$ Mo-K $\left._{\alpha}\right)$ $=0.757 \mathrm{~mm}^{-1}, F(000)=1028.0$, altogether 48617 reflexes up to $\mathrm{h}(-14 / 14), \mathrm{k}(-15 / 15), \mathrm{l}(-23 / 23)$ measured in the range of $3.898^{\circ} \leq 2 \Theta \leq 52.874^{\circ}$, completeness $=99.4 \%$, 9438 independent reflections, $R_{\text {int }}=0.0519,523$ parameters, 0 restraints, $R 1_{\mathrm{obs}}=0.0510, w R 2_{\mathrm{obs}}=0.1093, R 1_{\mathrm{all}}$ $=0.0707, w R 2_{\text {all }}=0.1205, \mathrm{GOOF}=1.080$, largest difference peak and hole: $0.48 /-0.54 \mathrm{e} \cdot \AA^{-3}$.

5,5'-(3',6'-Bis(4-(tert-butyl)phenyl)-[1,1':2',1"'-terphenyl]-4',5'-diyl)di-pyrimidine (6b): In a $50 \mathrm{~mL}$ RB Schlenk flask, tolane $3(0.074 \mathrm{~g}, 0.41 \mathrm{mmol})$ and tetracyclone $\mathbf{5 b}$ $(0.200 \mathrm{~g}, 0.40 \mathrm{mmol})$ were stirred at $295{ }^{\circ} \mathrm{C}$ in benzophenone ( $2 \mathrm{~g}$ ) under an argon atmosphere for $2 \mathrm{~h}$. Upon cooling to room temperature, the crude was dispersed in $n$-hexane $(3 \times 20 \mathrm{~mL})$ and the solutions decanted and subjected to column chromatography $\left(R_{f}=0.94, \mathrm{Et}_{2} \mathrm{O}\right)$. The brownish residue was recrystallized from $\mathrm{MeOH}$ to give $\mathbf{6 b}$ as colourless flakes $(0.183 \mathrm{~g}, 70 \%), \mathrm{mp}>300{ }^{\circ} \mathrm{C}$.

ATR-IR (neat): 3053, 3032, 2962, 2903(sh), 2870, 1599, 1579, 1548, 1513, 1494, 1462, 1443, 1422, 1414, 1398, 1385 , $1363,1342,1266,1202,1188,1155,1116,1099,1070,1052$, 1025, 996, 986, 949, 922, 910, 860, 842, 836, 817, 799, 780, $751,731,700 \mathrm{~cm}^{-1}$.

${ }^{1} \mathrm{H} \mathrm{NMR}\left(\mathrm{CDCl}_{3}, 400 \mathrm{MHz}\right): \delta=8.74\left(\mathrm{~s}, 2 \mathrm{H}, \mathrm{H}^{\mathrm{Py}-2}\right), 8.21$ $\left(\mathrm{s}, 4 \mathrm{H}, \mathrm{H}^{\mathrm{Py}-4 / 6}\right), 6.95-6.91\left(\mathrm{~m}, 4 \mathrm{H}, \mathrm{H}^{\mathrm{Ph}}\right), 6.88-6.83(\mathrm{~m}, 6 \mathrm{H}$, $\left.\mathrm{H}^{\mathrm{Ph}}\right), 6.82-6.78\left(\mathrm{~m}, 4 \mathrm{H}, \mathrm{H}^{\mathrm{Ph}}\right), 6.71-6.69\left(\mathrm{~m}, 4 \mathrm{H}, \mathrm{H}^{\mathrm{Ph}}\right), 1.11(\mathrm{~s}$, $\left.18 \mathrm{H}, \mathrm{H}^{\text {tert-Bu}}\right) \mathrm{ppm}$.

${ }^{13} \mathrm{C} \mathrm{NMR}\left(\mathrm{CDCl}_{3}, 101 \mathrm{MHz}\right): \delta=158.13,156.02,149.41$, $142.80,141.69,139.53,135.56,134.18,133.33,131.08$, 130.88, 126.90, 125.83, 124.43, 34.45, 31.18 ppm.

HRMS (MALDI): $m / z[\mathrm{M}+\mathrm{H}]^{+}$calcd for $\mathrm{C}_{46} \mathrm{H}_{43} \mathrm{~N}_{4}{ }^{+}$: 651.34822; found: 651.34855 .

Crystals suitable for X-ray diffraction were obtained from toluene/chloroform. Crystal data: $\mathrm{C}_{46} \mathrm{H}_{42} \mathrm{~N}_{4}, M_{\mathrm{r}}=1152.35 \mathrm{~g}$ $\mathrm{mol}^{-1}$, colourless block, $0.124 \times 0.339 \times 0.418 \mathrm{~mm}^{3}$, triclinic, 
space group P-1, $a=11.9779(6) \AA, \quad b=12.4389(7) \AA$, $c=15.1036(8) \quad \AA, \quad \alpha=66.814(3)^{\circ}, \quad \beta=70.215(3)^{\circ}$, $\gamma=62.424(3)^{\circ}, V=1799.54(17) \AA^{3}, T=149.98 \mathrm{~K}, Z=2$, $\rho_{\text {calcd. }}=1.201 \mathrm{Mg} / \mathrm{m}^{3}, \quad \mu\left(\mathrm{Mo}-\mathrm{K}_{\alpha}\right)=0.070 \mathrm{~mm}^{-1}, \quad F$ $(000)=692.0$, altogether 37543 reflexes up to $\mathrm{h}(-14 / 14), \mathrm{k}$ $(-15 / 15), 1(-18 / 18)$ measured in the range of $4.068^{\circ} \leq 2 \Theta \leq$ $52.708^{\circ}$, completeness $=99.7 \%, 7327$ independent reflections, $R_{\text {int }}=0.0880,488$ parameters, 3 restraints, $R 1_{\mathrm{obs}}=0.0508$, $w R 2_{\mathrm{obs}}=0.1189, \quad R 1_{\mathrm{all}}=0.0991, \quad w R 2_{\mathrm{all}}=0.1584, \quad \mathrm{GOOF}$ $=1.088$, largest difference peak and hole: $0.19 /-0.23 \mathrm{e} \cdot \AA^{-3}$.

5,5'-(5',6'-Bis(4-(tert-butyl)phenyl)-[1,1':4',1"'-ter-

phenyl]-2',3'-diyl)di-pyrimidine (6c): In a $50 \mathrm{~mL}$ RB Schlenk flask, tolane $3(0.096 \mathrm{~g}, 0.53 \mathrm{mmol})$ and tetracyclone $\mathbf{5 c}$ $(0.250 \mathrm{~g}, 0.50 \mathrm{mmol})$ were stirred at $295{ }^{\circ} \mathrm{C}$ in benzophenone $(2 \mathrm{~g})$ under an argon atmosphere for $2 \mathrm{~h}$. Upon cooling to room temperature, the crude was dispersed in $n$-hexane $(3 \times 20 \mathrm{~mL})$ and the solutions decanted. The brownish residue was subjected to column chromatography $\left(R_{f}\right.$ $\left.=0.86, \mathrm{Et}_{2} \mathrm{O}\right)$ and the collected fractions recrystallized from $\mathrm{MeOH}$ to give $\mathbf{6 c}$ as off-white flakes (0.299 g, 87\%), $\mathrm{mp}>300{ }^{\circ} \mathrm{C}$.

ATR-IR (neat): 3084, 3053, 3022, 2960, 2903, 2865, 1602, 1579, 1548, 1511, 1497, 1474, 1462, 1441, 1424, 1414, 1387, $1363,1340,1313,1270,1200,1186,1165,1153,1118,1097$, 1072, 1050, 1025, 1000, 990, 949, 920, 912, 842, 813, 799, $774,749,731,700,685,630,605,585,560,541,525,513$, $465,436 \mathrm{~cm}^{-1}$.

${ }^{1} \mathrm{H} \mathrm{NMR}\left(\mathrm{CDCl}_{3}, 400 \mathrm{MHz}\right): \delta=8.75\left(\mathrm{~s}, 2 \mathrm{H}, \mathrm{H}^{\mathrm{Py}-2}\right), 8.21$ $\left(\mathrm{s}, 4 \mathrm{H}, \mathrm{H}^{\mathrm{Py}-4 / 6}\right), 6.96-6.90\left(\mathrm{~m}, 6 \mathrm{H}, \mathrm{H}_{\mathrm{Ph}}\right), 6.86-6.81(\mathrm{~m}, 8 \mathrm{H}$, $\left.\mathrm{H}^{\mathrm{Ph}}\right), 6.68-6.65\left(\mathrm{~m}, 4 \mathrm{H}, \mathrm{H}^{\mathrm{Ph}}\right), 1.09\left(\mathrm{~s}, 18 \mathrm{H}, \mathrm{H}^{\text {tert-Bu}}\right) \mathrm{ppm}$.

${ }^{13} \mathrm{C} \mathrm{NMR}\left(\mathrm{CDCl}_{3}, 101 \mathrm{MHz}\right): \delta=158.17,156.12,148.60$, $143.23,141.58,138.85,136.34,134.12,132.97,131.25$, $130.63,127.60,126.50,123.65,34.25,31.22 \mathrm{ppm}$.

HRMS (MALDI): $m / z[\mathrm{M}+\mathrm{H}]^{+}$calcd for $\mathrm{C}_{46} \mathrm{H}_{43} \mathrm{~N}_{4}{ }^{+}$: 651.34822; found: 651.34848 .

Crystals suitable for X-ray diffraction were obtained from toluene/chloroform. Crystal data: $\mathrm{C}_{92} \mathrm{H}_{84} \mathrm{~N}_{8} \cdot 6 \mathrm{CHCl}_{3}$, $M_{\mathrm{r}}=2017.87 \mathrm{~g} \mathrm{~mol}^{-1}$, colourless fragment, $0.122 \times 0.186$ $\times 0.277 \mathrm{~mm}^{3}$, triclinic, space group P-1, $a=16.225(8) \AA$, $b=18.544(9) \quad \AA, \quad c=18.749(10) \quad \AA, \quad \alpha=64.96(3)^{\circ}$, $\beta=82.33(2)^{\circ}, \gamma=89.26(2)^{\circ}, V=5059(5) \AA^{3}, T=150.00 \mathrm{~K}$, $Z=2, \rho_{\text {calcd. }}=1.325 \mathrm{Mg} / \mathrm{m}^{3}, \mu\left(\right.$ Mo-K $\left.\mathrm{K}_{\alpha}\right)=0.535 \mathrm{~mm}^{-1}, F$ $(000)=2080.0$, altogether 92715 reflexes up to $\mathrm{h}(-19 / 19)$, $\mathrm{k}(-22 / 22), \mathrm{l}(-22 / 22)$ measured in the range of $3.784^{\circ} \leq 2 \Theta$ $\leq 50.064^{\circ}$, completeness $=99.5 \%, 17803$ independent reflections, $R_{\text {int }}=0.0683,1167$ parameters, 7 restraints, $R 1_{\mathrm{obs}}=0.0683, \quad w R 2_{\mathrm{obs}}=0.1585, \quad R 1_{\mathrm{all}}=0.1005, \quad w R 2_{\mathrm{all}}$ $=0.1848, \mathrm{GOOF}=1.015$, largest difference peak and hole: $1.59 /-1.53 \mathrm{e} \cdot \AA^{-3}$.

5,5'-(4,4"-Di-tert-butyl-5',6'-bis(4-(tert-butyl)phenyl)$\left[1,1^{\prime}: 2\right.$ ', 1"-terphenyl]-3',4'-diyl)dipyrimidine $(\mathbf{6 d})^{18}:$ In a $50 \mathrm{~mL}$ RB Schlenk flask, tolane $3(0.121 \mathrm{~g}, 0.66 \mathrm{mmol})$ and tetracyclone $\mathbf{5 d}(0.403 \mathrm{~g}, 0.66 \mathrm{mmol})$ were stirred at $295{ }^{\circ} \mathrm{C}$ in benzophenone ( $3 \mathrm{~g}$ ) under an argon atmosphere for $2 \mathrm{~h}$. Upon cooling to room temperature, the crude was subjected to flash chromatography, starting elution with a mixture of $\mathrm{Et}_{2} \mathrm{O} / n$-hexane $(4: 1)$ and upon removal of benzophenone with pure $\mathrm{Et}_{2} \mathrm{O}\left(R_{f}=0.96\right)$, a colourless solid that was recrystallized from $n$-hexane to give fine white needles ( $0.402 \mathrm{~g}, 80 \%), \mathrm{mp}>300{ }^{\circ} \mathrm{C}$.

ATR-IR (neat): 3042, 3032, 2958, 2905, 2865, 1900, 1612, $1579,1548,1513,1474,1464,1431,1392,1363,1268,1231$, $1202,1188,1167,1155,1120,1101,1050,1025,1019,994$, $943,933,918,856,846,832,782,731,688,630,613,570$, 562, 521, 469, 449, $428 \mathrm{~cm}^{-1}$.

${ }^{1} \mathrm{H} \mathrm{NMR}\left(\mathrm{CDCl}_{3}, 400 \mathrm{MHz}\right): \delta=8.75\left(\mathrm{~s}, 2 \mathrm{H}, \mathrm{H}^{\mathrm{Py}-2}\right), 8.23$ (s, $\left.4 \mathrm{H}, \mathrm{H}^{\mathrm{Py}-4 / 6}\right), 6.93-6.89$ (td, $\left.4 \mathrm{H}, \mathrm{H}_{\mathrm{Ph}}\right), 6.85-6.82$ (td, $4 \mathrm{H}$, $\left.\mathrm{H}^{\mathrm{Ph}}\right), 6.71-6.64\left(\mathrm{~m}, 8 \mathrm{H}, \mathrm{H}^{\mathrm{Ph}}\right), 1.11\left(\mathrm{~s}, 18 \mathrm{H}, \mathrm{H}^{\text {tert-Bu}}\right), 1.08$ (s, $\left.18 \mathrm{H}, \mathrm{H}^{\text {tert-Bu}}\right) \mathrm{ppm}$.

${ }^{13} \mathrm{C} \mathrm{NMR}\left(\mathrm{CDCl}_{3}, 101 \mathrm{MHz}\right): \delta=158.25,156.02,149.15$, $148.41,143.20,141.73,136.59,135.79,134.27,132.79$, $130.94,130.66,124.30,123.52,34.34,34.24,31.24$, $31.21 \mathrm{ppm}$.

HRMS (MALDI): $\mathrm{m} / \mathrm{z} \quad[\mathrm{M}]^{+}$calcd for $\mathrm{C}_{54} \mathrm{H}_{59} \mathrm{~N}_{4}{ }^{+}$: 763.47342; found: 763.47349 .

5-((5',6'-Diphenyl-4'-(pyrimidin-5-yl)-[1,1':2',1'-terphenyl]-3'-yl)ethynyl)-pyrimidine (7): In a $50 \mathrm{~mL}$ RB Schlenk flask, butadiyne $4(0.051 \mathrm{~g}, 0.25 \mathrm{mmol})$ and tetracyclone $\mathbf{5 a}$ ( $0.106 \mathrm{~g}, 0.28 \mathrm{mmol}$ ) were stirred at $230{ }^{\circ} \mathrm{C}$ in diphenyl ether (5 mL) under an argon atmosphere for $12 \mathrm{~h}$. Upon cooling to room temperature, the solvent was removed under reduced pressure and the crude subjected to column chromatography $\left(R_{f}=0.89, \mathrm{Et}_{2} \mathrm{O}\right)$, which gave a colourless powder that was recrystallized from methanol. Fine colourless needles were obtained $(0.031 \mathrm{~g}, 22 \%), \mathrm{mp}>300{ }^{\circ} \mathrm{C}$.

ATR-IR (neat): 3059, 3022, 2215, 1599, 1575, 1548, 1536, $1494,1443,1414,1396,1340,1313,1278,1262,1219,1182$, $1153,1118,1072,1050,1025,1000,986,968,910,865,844$, $823,811,782,774,753,739,727,696,655,628,595,558$, $543,517,506,478,451,432 \mathrm{~cm}^{-1}$.

${ }^{1} \mathrm{H} \mathrm{NMR}\left(\mathrm{CDCl}_{3}, 400 \mathrm{MHz}\right): \delta=9.03\left(\mathrm{~s}, 1 \mathrm{H}, \mathrm{H}^{\text {AlkPy-2}}\right), 8.97$ $\left(\mathrm{s}, 1 \mathrm{H}, \mathrm{H}^{\mathrm{Py}-2}\right), 8.65\left(\mathrm{~s}, 2 \mathrm{H}, \mathrm{H}^{\text {AlkPy-4/6 }}\right), 8.08\left(\mathrm{~s}, 2 \mathrm{H}, \mathrm{H}^{\mathrm{Py}-4 / 6}\right)$, 7.25-7.19 (m, $5 \mathrm{H}), 7.00-6.80(\mathrm{~m}, 15 \mathrm{H}) \mathrm{ppm}$.

${ }^{13} \mathrm{C} \mathrm{NMR}\left(\mathrm{CDCl}_{3}, 101 \mathrm{MHz}\right): \delta=158.24,157.92,156.93$, $156.73,144.73,143.19,142.41,141.28,139.64,139.11$, $138.98,138.38,135.73,134.31,131.18,131.05,130.96$, $130.59,127.75,127.55,127.27,127.12,127.05,126.83$, 126.22, 126.17, 121.80, 119.38, 95.13, 90.77 ppm.

HRMS (MALDI): $m / z[\mathrm{M}+\mathrm{H}]^{+}$calcd for $\mathrm{C}_{40} \mathrm{H}_{27} \mathrm{~N}_{4}{ }^{+}$: 563.22302; found: 563.22359 .

Crystals suitable for X-ray diffraction were obtained from toluene/chloroform. Crystal data: $\mathrm{C}_{40} \mathrm{H}_{26} \mathrm{~N}_{4}, M_{\mathrm{r}}$ $=562.65 \mathrm{~g} \mathrm{~mol}^{-1}$, colourless needle, $0.114 \times 0.186$ $\times 0.611 \mathrm{~mm}^{3}$, monoclinic, space group $\mathrm{P} 2 / \mathrm{n}, a=9.4859$ (6) $\AA, \quad b=14.0064(8) \AA, \quad c=22.7219(12) \AA, \alpha=90^{\circ}$, $\beta=99.350(2)^{\circ}, \gamma=90^{\circ}, V=2978.8(3) \AA^{3}, T=150.01 \mathrm{~K}$, $Z=4, \rho_{\text {calcd. }}=1.255 \mathrm{Mg} / \mathrm{m}^{3}, \mu\left(\mathrm{Mo}-\mathrm{K}_{\alpha}\right)=0.074 \mathrm{~mm}^{-1}, F$ $(000)=1176.0$, altogether 66514 reflexes up to $\mathrm{h}(-12 / 12)$, 
$\mathrm{k}(-18 / 18), \mathrm{l}(-29 / 29)$ measured in the range of $4.436^{\circ} \leq 2 \Theta$ $\leq 55.696^{\circ}$, completeness $=99.8 \%, 7081$ independent reflections, $R_{\text {int }}=0.1334$, 397 parameters, 0 restraints, $R 1_{\mathrm{obs}}=0.0947, \quad w R 2_{\mathrm{obs}}=0.2334, \quad R 1_{\mathrm{all}}=0.1133, \quad w R 2_{\mathrm{all}}$ $=0.2457, \mathrm{GOOF}=1.203$, largest difference peak and hole: $0.49 /-0.33 \mathrm{e} \cdot \AA^{-3}$.

\section{Funding Information}

Funded by the Deutsche Forschungsgemeinschaft (DFG, German Research Foundation) - Projektnummer 364549901-TRR 234 [B2].

\section{Acknowledgment}

N.M. kindly acknowledges S. Knoll for the synthesis of 3(mercaptopropyl)-functionalized silica for the purification of Sonogashira products.

\section{Supporting Information}

Supporting Information for this article is available online at https://doi.org/10.1055/a-1482-6190.

\section{References}

(1) Burnside, W. Theory of Groups of Finite Order. Cambridge University Press: Cambridge, 2012.

(2) Pólya, G.; Read, R. C. Combinatorial Enumeration of Groups, Graphs, and Chemical Compounds. Springer: New York, NY, 1987.

(3) Vij, V.; Bhalla, V.; Kumar, M. Chem. Rev. 2016, 116, 9565.

(4) Tomović, Z.; van Dongen, J.; George, S. J.; Xu, H.; Pisula, W.; Leclère, P.; Smulders, M. M. J.; De Feyter, S.; Meijer, E. W.; Schenning, A. P. H. J. J. Am. Chem. Soc. 2007, 129, 16190.

(5) Hiraoka, S.; Hisanaga, Y.; Shiro, M.; Shionoya, M. Angew. Chem. Int. Ed. 2010, 49, 1669.

(6) Steeger, M.; Lambert, C. Chem. Eur. J. 2012, 18, 11937.

(7) Traber, B.; Wolff, J. J.; Rominger, F.; Oeser, T.; Gleiter, R.; Goebel, M.; Wortmann, R. Chem. Eur. J. 2004, 10, 1227.

(8) Shukla, R.; Lindeman, S. V.; Rathore, R. Org. Lett. 2007, 9, 1291.

(9) Yong, L.; Butenschön, H. Chem. Commun. 2002, 2852.

(10) Kotha, S.; Brahmachary, E.; Lahiri, K. Eur. J. Org. Chem. 2005, 2005, 4741.

(11) Xiang, Y.; Wang, Q.; Wang, G.; Li, X.; Zhang, D.; Jin, W. Tetrahedron 2016, 72, 2574.

(12) Wijesinghe, L. P.; Perera, S. D.; Larkin, E.; Máille, G. M. Ó.; Conway-Kenny, R.; Lankage, B. S.; Wang, L.; Draper, S. M. RSCAdv. 2017, 7, 24163.

(13) Gregg, D. J.; Ollagnier, C. M. A.; Fitchett, C. M.; Draper, S. M. Chem. Eur. J. 2006, 12, 3043.

(14) Nagarajan, S.; Barthes, C.; Gourdon, A. Tetrahedron 2009, 65, 3767.
(15) Wijesinghe, L. P.; Lankage, B. S. Chem. Commun. 2014, 50, 10637.

(16) Suzuki, S.; Segawa, Y.; Itami, K.; Yamaguchi,J.Nat. Chem. 2015, 7, 227.

(17) Lungerich, D.; Reger, D.; Hölzel, H.; Riedel, R.; Martin, M. M. J. C.; Hampel, F.; Jux, N. Angew. Chem. Int. Ed. 2016, 55, 5602.

(18) Draper, S. M.; Gregg, D. J.; Madathil, R. J. Am. Chem. Soc. 2002, $124,3486$.

(19) Meitinger, N.; Mengele, A. K.; Witas, K.; Kupfer, S.; Rau, S.; Nauroozi, D. Eur. J. Org. Chem. 2020, 2020, 6555.

(20) Geng, Y.; Fechtenkötter, A.; Müllen, K.J. Mater. Chem. 2001, 11, 1634.

(21) Schreck, M. H.; Röhr, M. I. S.; Clark, T.; Stepanenko, V.; Würthner, F.; Lambert, C. Chem. Eur. J. 2019, 25, 2831.

(22) Tanaka, Y.; Akita, M. J. Organomet. Chem. 2018, 878, 30.

(23) Khan, F. A.; Wang, D.; Pemberton, B.; Talipov, M. R.; Rathore, R. J. Photochem. Photobiol., A 2016, 331, 153.

(24) Bhalla, V.; Vij, V.; Dhir, A.; Kumar, M. Chem. Eur. J. 2012, 18, 3765.

(25) Thomas, K. R. J.; Velusamy, M.; Lin, J. T.; Sun, S.-S.; Tao, Y.-T.; Chuen, C.-H. Chem. Commun. 2004, 20, 2328.

(26) Zou, Y.; Ye, T.; Ma, D.; Qin, J.; Yang, C. J. Mater. Chem. 2012, 22, 23485.

(27) Stępień, M.; Gońka, E.; Żyła, M.; Sprutta, N. Chem. Rev. 2017, 117, 3479.

(28) Wang, X.; Sun, G.; Routh, P.; Kim, D. H.; Huang, W.; Chen, P. Chem. Soc. Rev. 2014, 43, 7067.

(29) Gregg, D. J.; Bothe, E.; Höfer, P.; Passaniti, P.; Draper, S. M. Inorg. Chem. 2005, 44, 5654.

(30) Draper, S. M.; Gregg, D. J.; Schofield, E. R.; Browne, W. R.; Duati, M.; Vos, J. G.; Passaniti, P. J. Am. Chem. Soc. 2004, 126, 8694.

(31) Vo, T. H.; Perera, U. G. E.; Shekhirev, M.; Mehdi Pour, M.; Kunkel, D. A.; Lu, H.; Gruverman, A.; Sutter, E.; Cotlet, M.; Nykypanchuk, D.; Zahl, P.; Enders, A.; Sinitskii, A.; Sutter, P. Nano Lett. 2015, 15, 5770.

(32) Cai, J.; Pignedoli, C. A.; Talirz, L.; Ruffieux, P.; Söde, H.; Liang, L.; Meunier, V.; Berger, R.; Li, R.; Feng, X.; Müllen, K.; Fasel, R. Nat. Nanotechnol. 2014, 9, 896.

(33) Leitner, T. D.; Gmeinder, Y.; Röhricht, F.; Herges, R.; MenaOsteritz, E.; Bäuerle, P. Eur. J. Org. Chem. 2020, 2020, 285.

(34) Pfeffer, M. G.; Pehlken, C.; Staehle, R.; Sorsche, D.; Streb, C.; Rau, S. Dalton Trans. 2014, 43, 13307.

(35) Gregg, D. J.; Ollagnier, C. M. A.; Fitchett, C. M.; Draper, S. M. Chem. Eur. J. 2006, 12, 3043.

(36) Chebny, V. J.; Shukla, R.; Rathore, R. J. Phys. Chem. A 2006, 110, 13003.

(37) Alvarez, S. Dalton Trans. 2013, 42, 8617.

(38) Hübscher, J.; Seichter, W.; Gruber, T.; Kortus, J.; Weber, E. J. Heterocycl. Chem. 2015, 52, 1062.

(39) Georgiev, I.; Bosch, E.; Barnes, C. L.J. Chem. Crystallogr. 2004, 34, 859.

(40) Nwachukwu, C. I.; Patton, L. J.; Bowling, N. P.; Bosch, E. Acta Crystallogr., Sect. C: Cryst. Struct. Commun. 2020, 76, 458.

(41) Delaney, C.Ó Máille G. M.Twamley, B.; Draper, S. M. Org. Lett. 2016, 18, 88.

(42) Fort, E. H.; Donovan, P. M.; Scott, L. T.J. Am. Chem. Soc. 2009, 131, 16006.

(43) Sarkar, A.; Okada, S.; Nakanishi, H.; Matsuda, H. Helv. Chim. Acta 1999, 82, 138.

(44) Sheldrick, G. M. Acta Crystallogr., Sect. A: Found. Crystallogr. 2008, 64, 112.

(45) Sheldrick, G. M. Acta Crystallogr., Sect. C: Cryst. Struct. Commun. 2015, 71, 3 .

(46) Macrae, C. F.; Edgington, P. R.; McCabe, P.; Pidcock, E.; Shields, G. P.; Taylor, R.; Towler, M.; Van De Streek, J. J. Appl. Crystallogr. 2006, 39, 453. 